\title{
Numerical Study of a West African Squall Line Using a Regional Climate Model
}

\author{
Benjamin Kouassi ${ }^{1}$, Adama Diawara ${ }^{1}$, Yves K. Kouadio ${ }^{1}$, Guy Schayes ${ }^{2}$, Fidèle Yoroba ${ }^{1}$, \\ Anderson A. Kouassi ${ }^{1}$, Eric-Pascal Zahiri ${ }^{1}$, Paul Assamoi ${ }^{1}$ \\ ${ }^{1}$ Laboratory of Atmospheric Physics and Fluids Mechanic, University of Cocody, Abidjan, Côte d'Ivoire \\ ${ }^{2}$ Centre de Recherche sur la Terre et le Climat, G. Lemaître-TECLIM, Université Catholique de Louvain, \\ Ottignies-Louvain-la-Neuve, Belgium \\ Email: yves.kouadio@gmail.com
}

Received October 4, 2011; revised November 25, 2011; accepted December 9, 2011

\begin{abstract}
The squall line of 21-22 August 1992, documented during the HAPEX-Sahel campaign, is simulated using the regional atmospheric model (MAR). The simulated results are compared to observational data. The aim of this work is both to test the capacity of this model to reproduce tropical disturbances in West Africa and to use this model as a meteorological one. It allows simulating high moisture content in the lower layers. The MAR simulates well updrafts whereas downward currents are neglected. This result may be due to convective scheme used to parameterize the convection in the model. The forecast of stability indexes used to define violent storms shows that the model is able to reproduce the squall line. Despite some differences with the observational data, the model shows its ability to reproduce major characteristics of the mesoscale convective disturbances.
\end{abstract}

Keywords: Mesoscale; Meteorology; Model; Squall Line; Simulation

\section{Introduction}

The climate in West Africa is characterized by high variability over a wide range of scale. The most striking example is the transition from a wet period during 19501968 to a period of rainfall deficit from the early 1970 s $[1,2]$. The drought caused starvations and destabilized the local economy based on agricultural resources. At this effect, numerous studies were undertaken to both establish the cause and to identify the main mechanisms of the climate variability in that region. For instance, some studies $[3,4]$ demonstrated that the main cause of the interannual variability of the rainfall was related to the number of convective systems. These disturbances represent extreme weather events in the Sahel region where they account for more than $90 \%$ of the rainfall [5]. For a better study of these phenomena, a tool seems necessary to specifically address the major processes and integrate information from a large scale. Regional climate models seem well suited for this experiment.

Some studies of the extreme weather events using regional climate models were successfully conducted. For instance, the simulation of the African wave disturbances during 8-15 August 1988 [6] showed that the dynamics and the physics of the model used seems to be more important than the lateral boundary conditions. The extreme events of temperature, storm and thunderstorms in Be- lgium, and the precipitations over the Lake Victoria in the Central Africa were also investigated [7] with the regional atmospheric model (hereafter MAR). The frontal systems, the development and the deepening of the depressions were reproduced successfully during the events of winter 1990 in Europe. The refinement of the horizontal resolution of the model improved the representation of low pressure systems characterized by rapid intensification. The model also helped to simulate the temporal evolution of the estimated amount of the rainfall in Belgium at different horizontal resolutions of about $10 \mathrm{~km}, 25 \mathrm{~km}$ and $50 \mathrm{~km}$. In the case of the Lake Victoria in Central Africa, the MAR allowed to qualitatively study the patterns of the convective parameterization. It represented well the diurnal cycle of the cloudy disturbance and the rainfall over the lake. It also highlighted the role of land and lake breezes and that of the katabatic and anabatic winds. In the West Africa case, several works were undertaken with this regional climate model. The study of Ramel et al. [8] showed that MAR reasonably well reproduced the monsoon jump which is associated with the shift of the Saharan heat low between the Sahelian and the Saharan areas. Vanvyve et al. [9] studied the internal variability of the model illustrated by the difference between two 1-year simulations and their initial conditions. This analysis showed a concomitant increase between the signal due to internal variability and 
the averaging period or spatial scale. This occurred more rapidly for variations in precipitation, which appeared essentially random, than for dynamical variables, which showed some organisation on larger scales. Ramel [10] also used MAR to simulate the main features of the West African rainfall regime. He showed that the simulated rainfall was in agreement with observation for time scales larger than 3 - 5 days. Despite the good results obtained with the model, the simulated moisture was more important in the lower layers than the observations. Moufouma-Okia [11] explained this difference by the errors of the large-scale lateral forcing due to the input ERA-40 reanalyses.

In this work, the squall line during 21-22 August 1992 documented during the HAPEX ${ }^{1}$-Sahel experiments [12] is simulated with MAR. This model is implemented in the laboratory of atmospheric physics and fluids mechanic at the University of Cocody (Côte d'Ivoire) through a Belgian cooperation. The study aims to represent extreme events which are squall lines for the tropical region of West Africa. The originality of this work is to represent sub-grid phenomena with a climate model. That will allow to analyze the behaviour of the model and to determine its limits and abilities to reproduce such atmospheric disturbances. The analysis of the behaviour of the model at the meteorological scale will constitute a preliminary step to use this climatic model as a meteorological one. To that effect, the duration of the model integration which does not exceed 4 days allows taking into account the deep convection in the climate simulations.

In the first part of the simulation analysis, the characteristics of the selected squall line are studied. We describe this disturbance through the cloud coverage, the barotropic and baroclinic instabilities of the African easterly jet and both the vertical profiles and the currents in the squall line. In the second part of the investigation, a study of the impact on the environment is undertaken. Studies of a set of stability indexes allow determining the probability and the intensity of the development of the convection and evaluating the associated weather phenomena at the synoptic scale.

This manuscript is outlined as follows: An overview of the model description and the data sets are presented in the second section. The early simulation of the squall line is described and discussed in the third section. A conclusion is provided in the last section.

\section{Materials and Method}

\subsection{Overview of the Description of the Regional Atmospheric Model}

MAR [13] is a hydrostatic model in which the vertical

${ }^{1}$ Hydrologic Atmospheric Pile Experiment coordinate $\sigma$ is the normalized pressure used to better represent the topography. MAR is forced by the European Centre for Medium-range Weather Forecast (EC MWF) reanalyses. Various schemes are used to perform prognostics variables which are given by the Equation (1).

$$
\begin{aligned}
F_{\psi}= & -\left(1 / p^{*}\right) \\
& \times\left[\partial\left(p^{*} \overline{u^{\prime} \psi^{\prime}}\right) / \partial x+\partial\left(p^{*} \overline{v^{\prime} \psi^{\prime}}\right) / \partial y+\partial\left(\overline{\sigma^{\prime} \psi^{\prime}}\right) / \partial \sigma\right]^{(1)}
\end{aligned}
$$

This equation gives the unresolved processes that are the hydrological cycle, the turbulent transfers, the convection, the radiative and the dissipation processes. In Equation (1), $\psi$ represents the prognostic variables and $u$, $v$ and $\theta$ are respectively the water vapour, the liquid water and the ice. The advection terms are calculated from the primitive equations discretized by the numerical "leap frog" and the semi-lagrangian schemes. The dynamic relaxation scheme $[14,15]$ pulls the prognostic variables towards the large scale fields. At the top of the model, the damping layer $[16,17]$ is used to minimize the reflections. The hydrological cycle of MAR [18] is based on the Kessler scheme [19-21] whereas the Bechtold scheme [22] is used to parameterized the sub-grid convection. This mass flow scheme is a one-dimensional cloud model proposed by Kain and Fritsch [23], in which the convection is triggered by local instability and the precipitant cloud is represented by vertical currents. The coupling between the convection scheme and the microphysics of the model allows to take into account the detrainment of cloudy water and the prognostic ice in the simulation of the precipitations at the grid scale. The closing of the convection scheme is based on the available convective potential energy (hereafter CAPE).

For our experiments, the model is forced with ERA-40 reanalyses of the ECMWF on the lateral edges with a regular recall each six hours. It is initialized on $19 \mathrm{Au}-$ gust 1992 at 00:00 UT considered as a spin-up. The calculations are integrated over 4-day period until $23 \mathrm{Au}-$ gust 1992 on a $40 \mathrm{~km}$ horizontal scale.

\subsection{Observational Data}

The Meteosat-4 images are used to study the squall line over West Africa. This dataset is available in 3-hour time intervals at full spatial resolution $(10 \times 10 \mathrm{~km})$ in the infrared channel. The input data used to initialize the model are from the ERA-40 fields of the ECMWF reanalyses [24]. Synoptic sounding data from the station of Niamey $\left(2.16^{\circ} \mathrm{E} ; 13.47^{\circ} \mathrm{N}\right)$ come from the database stored at the University of Wyoming [25]. The bad sounding data during 21 august at 00:00 UT and 22 August constrained us to use only those obtained during 21 August 1992 at 12:00 UT. 


\section{Results}

\subsection{Location of the Squall Line}

Satellite images and simulated cloud coverage: The characteristics of the squall lines (SL) over West Africa were studied for the first time by Houze [26] in the Gulf of Guinea during the $\mathrm{GATE}^{2}$ experiments and later by Roux [27] in the north of Côte d'Ivoire during COPT81 ${ }^{3}$. Using satellite images, Desbois et al. [28] studied the displacements of a SL between Tchad and Senegal and Laing et al. [29] estimated the rainfall contribution of a convective cluster in the Sahel. SLs are the more violent phenomena which caused $90 \%$ of the Sahel rainfall $[4,5]$. The passage of a SL is marked by an abrupt jump of the pressure followed by a rapid change in the direction of the wind. Finally, a decrease of the temperature, an intensification of the wind and strong precipitations are observed [30]. On a satellite image, SLs are easily spotted because 1) they have a sharper border line on their western edge, and 2) they move westward in West Africa [31]. Following these both criteria, the SL of 21 August 1992 is studied using the Meteosat-4 images over the West African region. This date is used according to the available synoptic sounding data.

The left panels on Figure 1 present the 3-hourly evolution of the cloud coverage from 12:00 UT to 21:00 UT in the Meteosat-4 images. A SL is observed in the north-western region of Nigeria at $6^{\circ} \mathrm{E}-13^{\circ} \mathrm{N}$. The size of the atmospheric disturbance increased when moving westward in the successive images. At 21:00 UT, the SL covered some regions of Benin, Burkina Faso, Mali, Niger and Nigeria. The right panels on Figure 1 illustrate the simulated water concentration from the non-precipitating cloudy water and cloudy ice at $9000 \mathrm{~m}$ level. Two convective clusters participated by merging to the initiation and the development phases of the SL observed in the north-western region of Nigeria at $6^{\circ} \mathrm{E}-13^{\circ} \mathrm{N}$ (see left panel). The first cell is simulated in the northern area of the Jos plateau around $7^{\circ} \mathrm{E}-9^{\circ} \mathrm{E} ; 10^{\circ} \mathrm{N}-12^{\circ} \mathrm{N}$, and the second one around $8^{\circ} \mathrm{E}-10^{\circ} \mathrm{E} ; 17^{\circ} \mathrm{N}-18^{\circ} \mathrm{N}$ over the Air mountainous region. The simulated SL seemed to be shifted eastward when comparing with the satellite image. That is explained by the 30-minutes lag between the model outputs and the satellite images. This time step, used for the deep convection adjustment in the Bechtold scheme, is necessary to remove the CAPE from the mesh grid. It corresponds also to the displacement of the disturbance between two grids.

The $650 \mathrm{hPa}$ Horizontal wind and pressure fields: Figure 2 illustrates the $650 \mathrm{hPa}$ wind vectors and pressure fields (shaded area) at 12:00 UT during 21 August

$\overline{{ }^{2} \text { (Global Atmospheric Research Program) Atlantic Tropical Experiment }}$ on the East Atlantic.

${ }^{3}$ Tropical Major Convection, in Korhogo in the North of Côte d'Ivoire.
1992. The simulated cyclonic area, at $5^{\circ} \mathrm{E}-15^{\circ} \mathrm{E} ; 10^{\circ} \mathrm{N}-$ $16^{\circ} \mathrm{N}$ in the Northern region of Nigeria, is coincident with the position of the SL at this date (see Figure 1). Strong westward flow which corresponds to the African easterly jet (AEJ) is noted towards $16^{\circ} \mathrm{N}$. A disturbance embedded in the flow is localized ahead the cyclonic area between $5^{\circ} \mathrm{W}-0^{\circ} \mathrm{E} ; 16^{\circ} \mathrm{N}-20^{\circ} \mathrm{N}$. This phenomenon, called easterly wave, is a disturbance of the wind field at $650 \mathrm{hPa}$. It plays an important role on Africa and on tropical Atlantic climate. It promotes and/or organizes

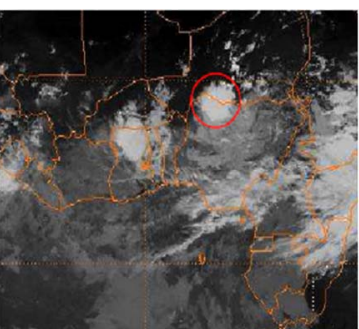

(a) Satellite Image 12:00 UTC

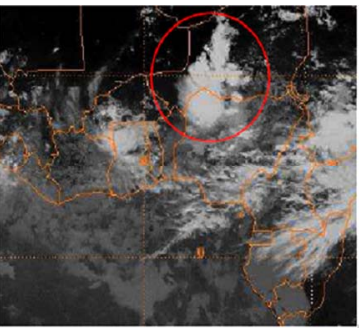

(c) Satellite Image 15:00 UTC

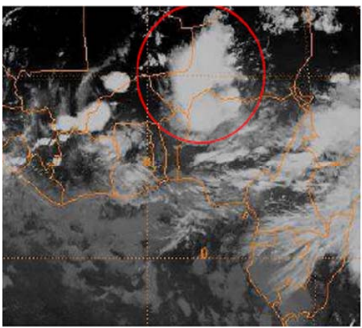

(e) Satellite Image 18:00 UTC

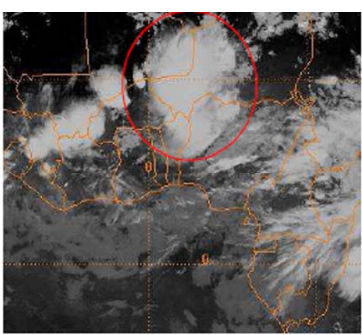

(g) Satellite Image 21:00 UTC

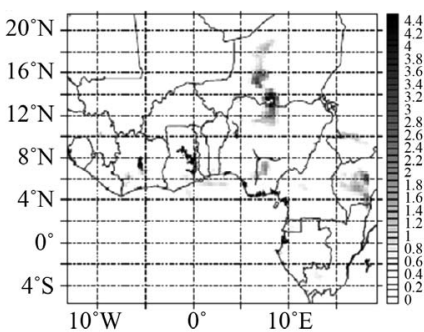

(b) MAR model output 12:00 UTC

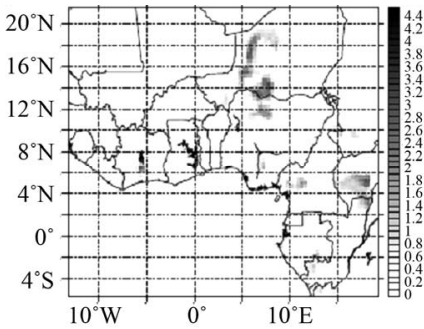

(d) MAR model output 15:00 UTC

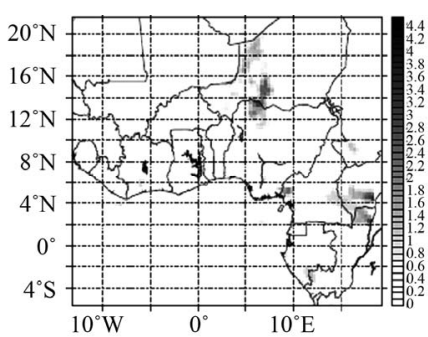

(f) MAR model output 18:00 UTC

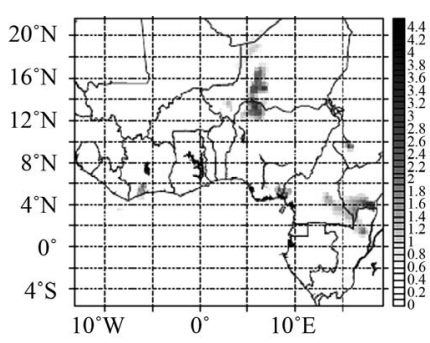

(h) MAR model output 21:00 UTC
Figure 1. (Left) The 3-hourly evolution of the cloud coverage at (a) 12:00 UT; (c) 15:00 UT; (e) 18:00 UT and (g) 21:00 UT of the Meteosat-4 images. The red circle shows the studied squall line. (Right) The water concentration $\left(\mathrm{g} \cdot \mathrm{kg}^{-1}\right)$ from the non-precipitating cloudy water and cloudy ice at $9000 \mathrm{~m}$ level simulated by the MAR at (b) 12:00 UT; (d) 15:00 UT; (f) 18:00 UT and (h) 21:00 UT. 


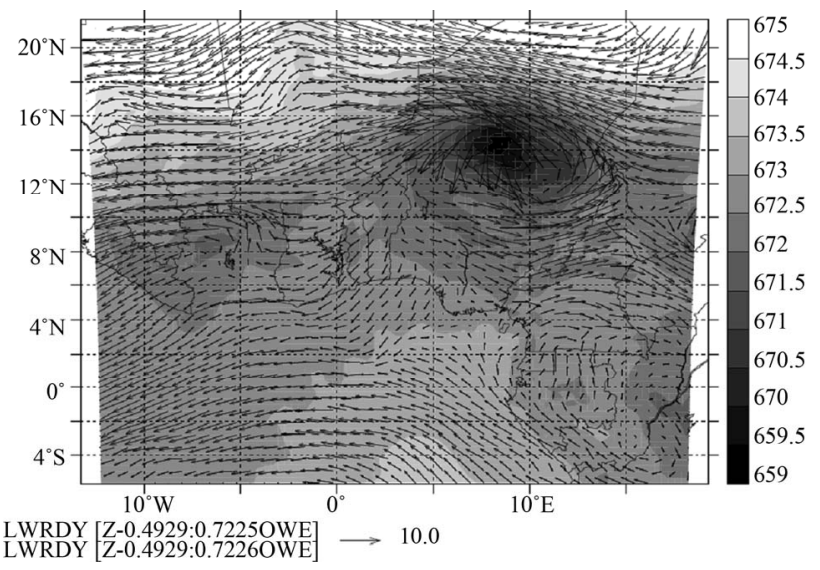

Figure 2. The $650 \mathrm{hPa}$ wind $\left(\mathrm{m} \cdot \mathrm{s}^{-1}\right.$; vector) and pressure (hPa, shaded) fields simulated by the MAR at 12:00 UT during 21 August 1992.

the convection that is a favourable environment for the birth and the development of the SLs and sometimes for the tropical Atlantic cyclones [32,33]. The simulated pressure field showed the talweg of the easterly wave which coincided with the wind disturbance. Note that the talweg is a depression in which the isobars form a " $\mathrm{V}$ " and the pressure decreases when moving to the concavity. The SL position, which is also coincident with the minimum pressure was previously analysed by Reed et al. [34] and by Barnes and Sieckman [35]. These authors argued that rapid SLs formed and reached their mature phase ahead of the talweg whereas slow SLs are observed at the rear of it.

\subsection{Barotropic and Baroclinic Instability in the African Easterly Jet}

Figure 3 shows the altitude-latitude diagram of the simulated potential vorticity (PV) and zonal wind along $7.5^{\circ} \mathrm{S}-25^{\circ} \mathrm{N}$, averaged between $5^{\circ} \mathrm{W}-10^{\circ} \mathrm{W}$. Three vortices representted by positive PV are noted. The first one extended from the surface up to $6000 \mathrm{~m}$ at $15^{\circ} \mathrm{N}$ of latitude. It is located in the vicinity of the AEJ core that coincides with the negative PV [36]. A less intense second vortex is localized around $13^{\circ} \mathrm{N}$ from $1000 \mathrm{~m}$ to $7000 \mathrm{~m}$. The third one is as intense as the first vortex and is noted at $10^{\circ} \mathrm{N}$ from $4000 \mathrm{~m}$ to $8000 \mathrm{~m}$. Reversal signs of $\mathrm{PV}$, marked by a northward succession of negative and positive values of PV, are simulated on the AEJ area between $10^{\circ} \mathrm{N}$ to $20^{\circ} \mathrm{N}$ [37]. Such result is a condition for barotropic and baroclinic instabilities [38].

\subsection{Vertical Profile and Currents in the SL}

Figure 4 illustrates the vertical cross-section of the zonal water content (shaded area), the zonal cloud structure (isolines) and the vertical motions of the wind (arrows) in the simulated SL during 21 August 1992 at 15:00 UT.

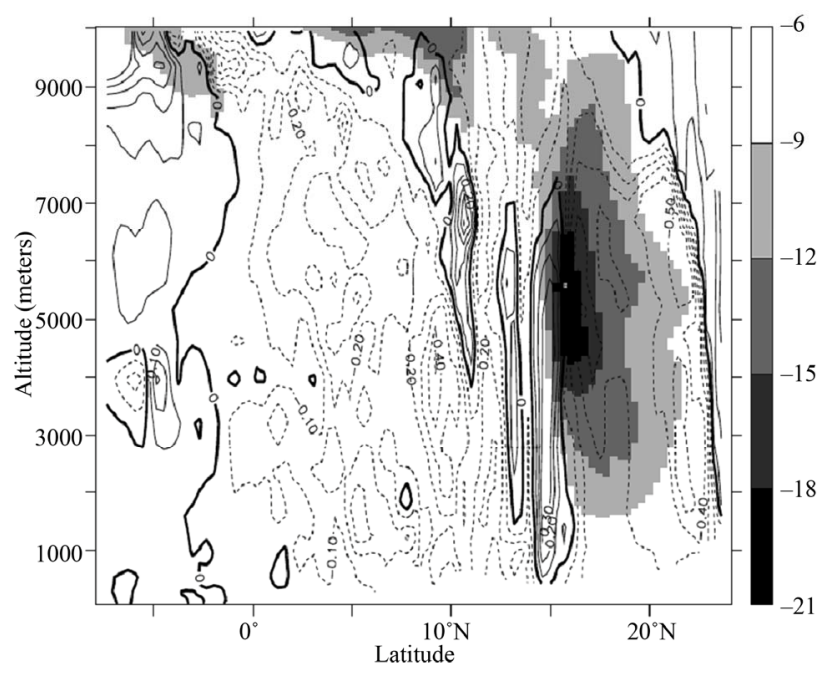

Figure 3. The altitude-latitude diagram of the simulated potential vorticity (PVU, isoline) and zonal wind $\left(\mathrm{m} \cdot \mathrm{s}^{-1}\right.$, shaded) along $7.5^{\circ} \mathrm{S}-25^{\circ} \mathrm{N}$, averaged between $5^{\circ} \mathrm{W}-10^{\circ} \mathrm{W}$.

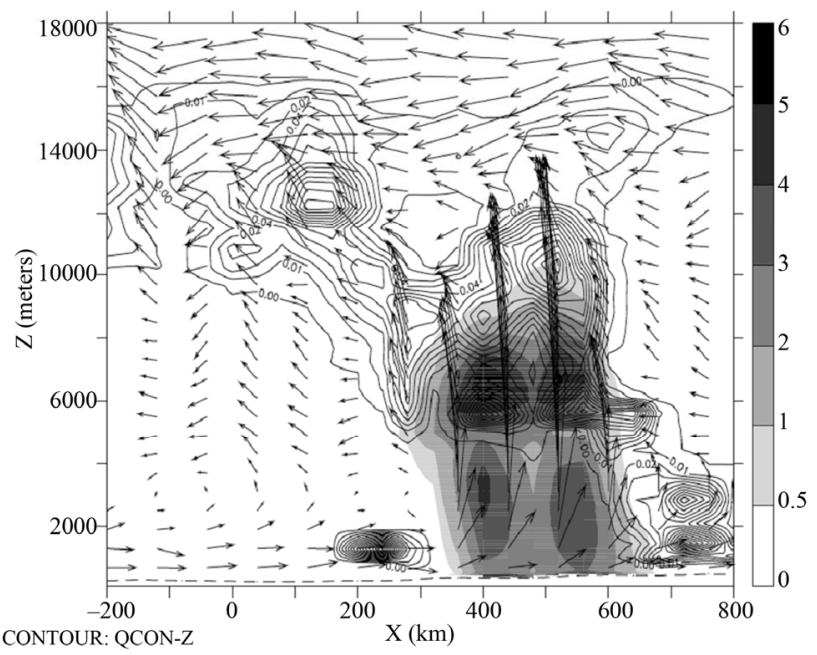

Figure 4. Vertical cross-section of the zonal water content $\left(\mathrm{g} \cdot \mathrm{kg}^{-1}\right.$; shaded), the zonal cloud structure (isolines) and the vertical motions of the wind $(U, W \times 100$; vector $)$ in the simulated SL during 21 August 1992 at 15:00 UT.

This time is related to the merging of the two cells observed at 12:00 UT. The vertical component of the wind is multiplied by a factor of 100 to better represent the upward current. Such calculations are performed to take into account the vertical acceleration that is neglected by the hydrostatic model.

The SL anvil is more developed in the front side than in the rear side between the vertical levels 10,000 $16,000 \mathrm{~m}$. The water content extended from the surface to $12,000 \mathrm{~m}$ and is composed by two cells localized approximately at $6000 \mathrm{~m}$. This zone represented the area of perturbation and precipitations [39]. The convective and the stratiform regions could not be differentiated because of the compact and confused shape of the SL. 
Strong convective scale and mesoscale updraft currents are noted between $300 \mathrm{~km}$ and $600 \mathrm{~km}$ at the horizontal scale. Those currents exist above both cells of water content from the surface up to $15,000 \mathrm{~m}$. No downward currents are practically noted, excepted those in front of the cloud at $300 \mathrm{~km}$ into the layer $2000-6000 \mathrm{~m}$. The dynamic organization of the squall line indicates an eastward flow around $2000 \mathrm{~m}$ and a westward one above $4000 \mathrm{~m}$. This opposite direction of the flows creates a vertical wind shear in front of the SL. The interaction between the updraft current in the SL and the wind shear engenders eddies which support the vertical currents inside the squall line.

An undulation is simulated inside the levels $10,000 \mathrm{~m}$ $14,000 \mathrm{~m}$, at the horizontal scale of $-200 \mathrm{~km}$ to $200 \mathrm{~km}$, and indicates the presence of gravity wave. The turbulent phenomena shown by the wind roll at the top of the atmospheric boundary layer are also simulated between $2000 \mathrm{~m}$ and $4000 \mathrm{~m}$. The configuration of the atmosphere in the lower and the middle layers is the characteristic of a Kelvin-Helmoltz wave. This last instability generally occurs at the interface between the atmospheric boundary layer and the free atmosphere. It generates gravity waves whose trapping involves the release of the convection.

Figure 5 shows the vertical cross-section of the difference between the potential temperature at 15:00 UT and at 00:00 UT. The difference is also used to illustrate the perturbation into the SL. In the immediate environment of the cloud, two characteristics of the difference of the potential temperature are simulated. The first one occurs in the lower layers from the surface up to $4000 \mathrm{~m}$ and, presents negative differences below and in front of the SL. This difference reaches $-4^{\circ} \mathrm{K}$ between $200 \mathrm{Km}$ and $600 \mathrm{~km}$. That means a decreasing of the temperature

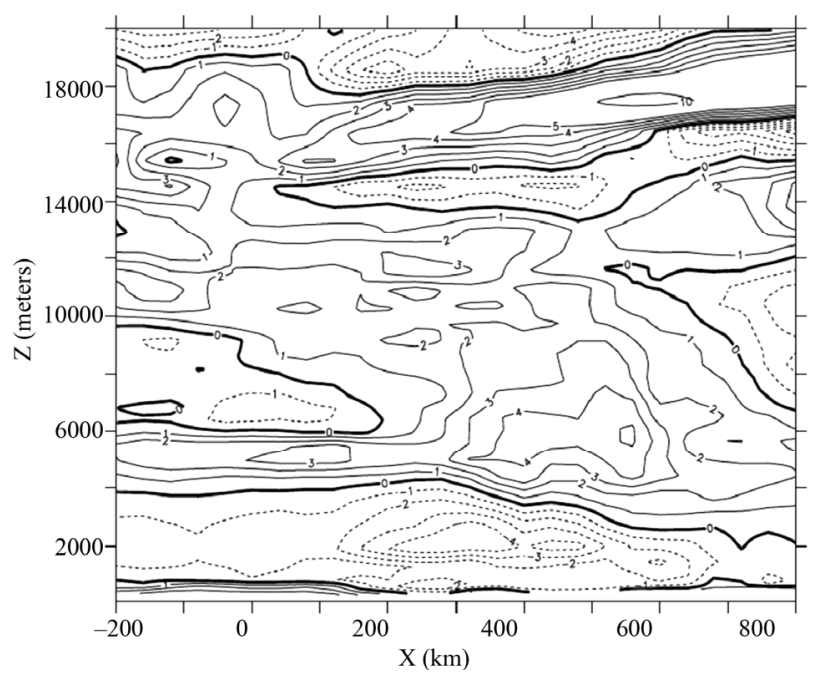

Figure 5. Vertical cross-section of the difference between the potential temperature (Kelvin) at 15:00 UT and at 00:00 UT. due to the cold density current [40] which stretches to the ground and forms a divergent flow. The second chara-cteristic, at the top of the cloud, indicates a positive difference due to the heating of the water vapour condensation. Others succession of cold and heat layers due to the intrusion of air are simulated above $14,000 \mathrm{~m}$.

\subsection{Impact of the Squall Line on the Environment: Analysis on Niamey Station}

It is known that convective events impact on synoptic situations which could be the large-scale vertical velocity, the moisture convergence in the lower layers and the atmospheric instabilities [41]. A diagnostic study of such situations includes the analysis of the static instability using sounding data and thermodynamic diagrams. This section aims to determine 1) the probability and the intensity of the development of the convection and 2) to evaluate the associated weather phenomena at the synoptic scale.

\subsubsection{Sounding Data from Observation and Simulation at Niamey}

Figure 6 shows the sounding profile at 12:00 UT at the station of Niamey $\left(2.16^{\circ} \mathrm{E} ; 13.47^{\circ} \mathrm{N}\right)$ for the simulated data (top panel) and for the observation (bottom panel). Some differences are observed between the condensation level (LCL), the convective condensation level (CCL), the free convection level (LFC) and the thermal level (EL) of both type of data (Table 1). Those levels indicate the different characteristics of the development of an atmospheric particle from the lower layers to the upper layers. The profiles of the specific humidity (Figure 7) of the ERA-40 reanalysis (dashed short line), the simulation (solid line) and the sounding (dashed long line) explain the difference noted between the observation and the simulation of the LCL, the CCL and the LFC. ERA-40 reanalyses and simulation data are higher than that of the observation from the surface up to $875 \mathrm{hPa}$ and to 750 $\mathrm{hPa}$ successively. Note that the specific humidity is related to the mixing ratio. This last parameter allows to determine the wet adiabat from which the atmospheric particle rises from LCL to EL. Thus, when the mixing ratio is high, the positioning of the different levels lowers for the same profile of temperature.

The observational EL is above the simulated level. Moreover, the wet adiabat is shifted rightward when comparing it with the observation. This is explained by the important moisture simulated in the lower layers. Moufouma-Okia [11] showed that this moistening in MAR is influenced by the moisture field of ERA-40 reanalyses that is introduced each six hours by the model. Thus, the model inherited the errors of the large-scale lateral forcing due to that input data. Diongue et al. [42] also found similar behaviour for moisture for other analyses with 


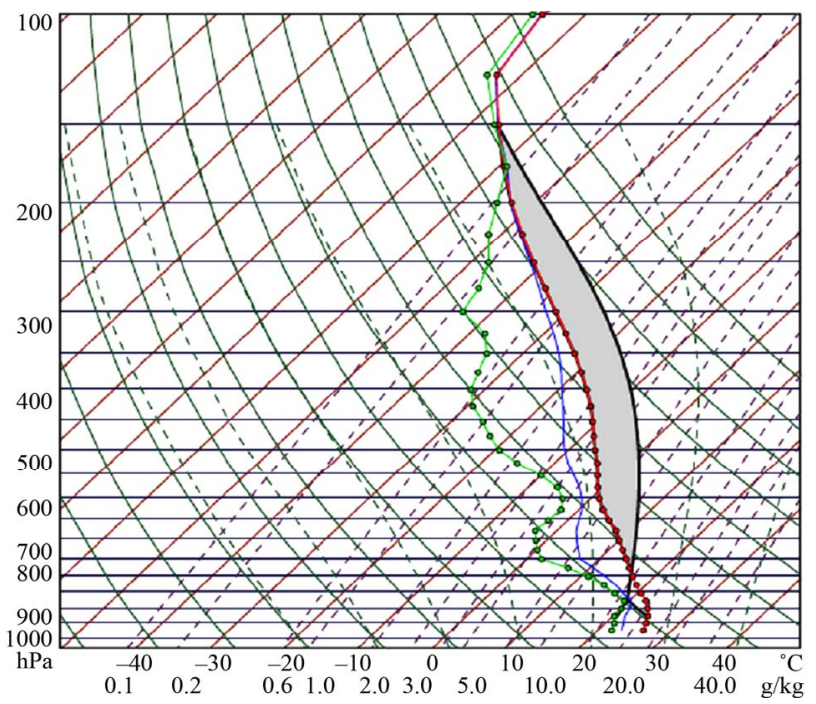

(a) Sounding from MAR model

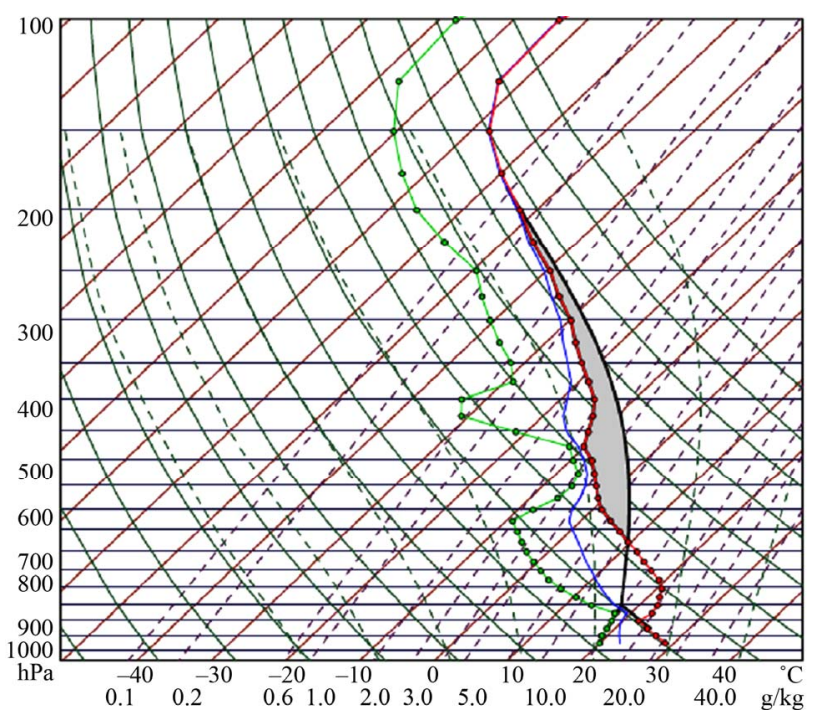

(b) Sounding from observations (OBS)

Figure 6. The sounding profiles at 12:00 UT at the station of Niamey $\left(2.16^{\circ} \mathrm{E} ; 13.47^{\circ} \mathrm{N}\right)$ for the simulated data (a) and for the observation (b). The condensation level (LCL), the convective condensation level (CCL), the free convection level (LFC) and the thermal level (EL) are by black filled circles. The state curve (red), the dewpoint (green), the moist adiabatic (black), the wet bulb (blue) and the CAPE (shaded area) are represented.

Table 1. Different characteristic levels from sounding (OBS) and simulation (MAR) at Niamey during 21 August 1992 at 12:00 UT.

\begin{tabular}{ccccc}
\hline \multirow{2}{*}{ Levels } & \multirow{2}{*}{$\begin{array}{c}\text { MAR } \\
(\mathrm{hPa})\end{array}$} & \multicolumn{3}{c}{ Simulation and Observation } \\
\cline { 3 - 5 } & & OBS (hPa) & $\begin{array}{c}\text { Difference } \\
\text { MAR-OBS (hPa) }\end{array}$ & $\begin{array}{c}\text { Difference } \\
\text { MAR-OBS (m) }\end{array}$ \\
\hline LCL & 915 & 856 & 59 & 500 \\
CCL & 825 & 734 & 91 & 900 \\
LFC & 788 & 674 & 114 & 1000 \\
EL & 751 & 184 & -33 & -1600 \\
\hline
\end{tabular}

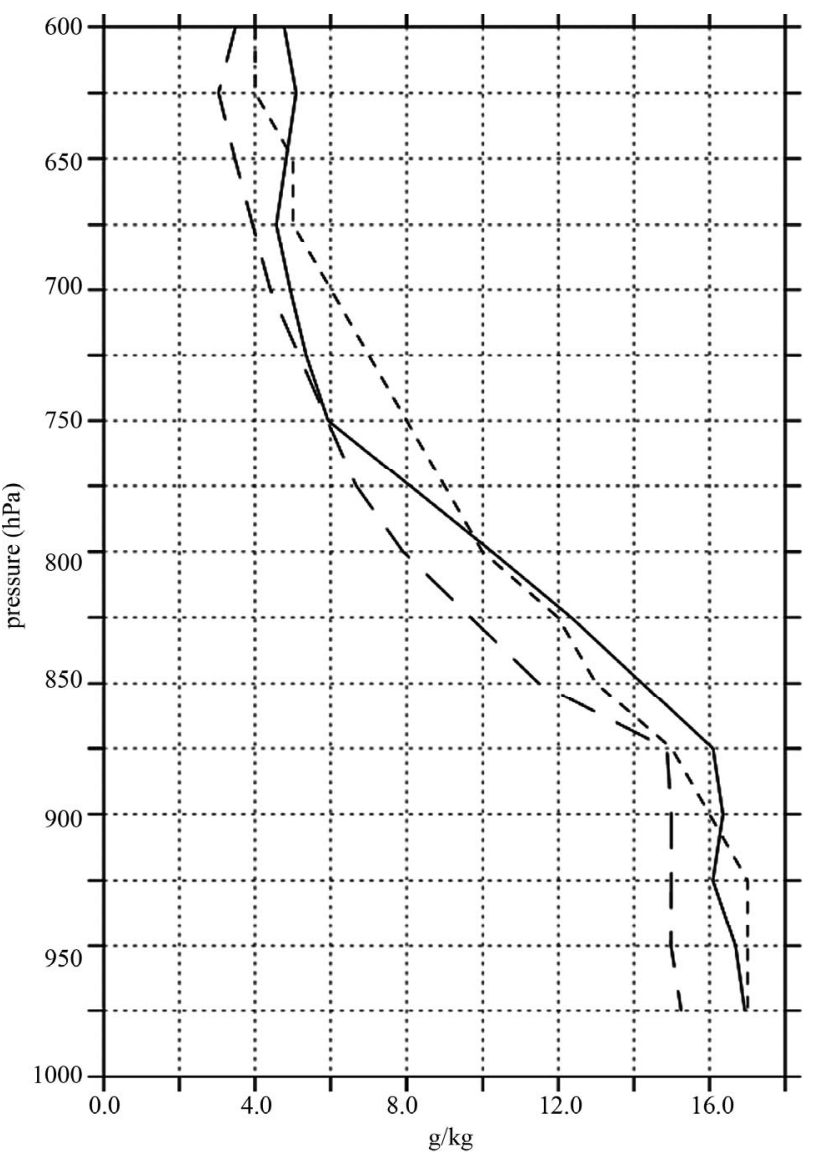

Figure 7. The profile of the specific humidity from sounding (dashed long line), ERA-40 reanalyses (dashed short line) and simulation (solid line) at Niamey during 21 August 1992 at 12:00 UT.

ERA-15. To overcome this problem, the authors used the corrected input data in their mesoscale model to avoid spurious absolute and conditional convective instabilities. Such analyses were not undertaken in the case of our experiment, since the first objective of this work was to test the ability of MAR to reproduce mesoscale phenomena. However, it would still be better if the vertical repartition of moisture is improved. This will be done in a coming work.

\subsubsection{Stability Indexes of Forecast of Storms}

The probability of the atmospheric disturbance occurrence is evaluated by studying several stability indexes during 21 August 1992. There are performed at 12:00 UT at the station of Niamey $\left(2.16^{\circ} \mathrm{E} ; 13.47^{\circ} \mathrm{N}\right)$ by using simulated and observational sounding data (see Figure 6) (Table 2).

The CAPE: The simulated CAPE (2232 $\left.\mathrm{J} \cdot \mathrm{kg}^{-1}\right)$ is higher than the observation $\left(942 \mathrm{~J} \cdot \mathrm{kg}^{-1}\right)$. When looking at the thresholds given by the abacus, the model indicates a moderate instability of the atmosphere that allows moderate storm. In the case of the observation, the atmosphere 
Table 2. Stability Indexes from sounding (OBS) and simulation (MAR) at Niamey during 21 August 1992 at 12:00 UT.

\begin{tabular}{ccc}
\hline \multirow{2}{*}{ Indexes } & \multicolumn{2}{c}{ Simulation and Observation } \\
\cline { 2 - 3 } & MAR & OBS \\
\hline CAPE $\left(\mathrm{J}^{\mathrm{kg}} \mathrm{kg}^{-1}\right)$ & 2232 & 942 \\
$\mathrm{CIN}\left(\mathrm{J} \cdot \mathrm{kg}^{-1}\right)$ & -36 & -259 \\
$\mathrm{LI}$ & -5.2 & -4.2 \\
$\mathrm{CIN}$ & 33 & 28 \\
\hline
\end{tabular}

with marginally instability is related to the presence of thunderstorm with low intensity. The comparison of both soundings (see Figure 6) reveals that the shape of the simulated CAPE is larger and longer than that of the observation. This means a more developed SL, stronger updrafts and a more favourable environment to create heavy precipitations. Let us also note that MAR overestimates the power of the event. This overestimation is due to the Bechtold scheme in which the CAPE is calculated with the potential temperature without additional updrafts. That method induces greater value of the CAPE than with a classical method in which the virtual temperature is used.

The convective inhibition index: The convective inhibition index (CIN) is known as the energy needed by an atmospheric particle to reach the LFC. The CIN behaves like a lid and is an indicator of the violent areas of ascent within the cloud. The simulated CIN $\left(-36 \mathrm{~J} \cdot \mathrm{kg}^{-1}\right)$ identifies a moderate inhibition that makes possible the development of SL and thunderstorm. For the observational data, the CIN $\left(259 \mathrm{~J} \cdot \mathrm{kg}^{-1}\right)$ is lower than $200 \mathrm{~J} \cdot \mathrm{kg}^{-1}$. This last threshold corresponds to a null probability for the development of a storm.

The lifted index: The lifted index (LI) is an indicator of the rising of the air mass [43]. When the temperature of an atmospheric particle is higher than that of the environment, it evolves rightward of the ambient air on a thermodynamic diagram. On the SkewT diagram, LI is determined with the mixing ratio of the first wet layers above the ground and with the surface temperature. It is calculated as the difference between the air temperature at $500 \mathrm{hPa}$ and that determined with the LCL through a SkewT diagram. LI is -5.2 and -4.2 for the simulation and the observation respectively. The model LI indicates a higher atmospheric instability with a risk of violent storm whereas the observation shows a moderate risk.

The KI index: The KI index [44] is a useful tool to diagnose the convective potential. It takes into account the vertical distribution of the moisture at $850 \mathrm{hPa}$, the depression of the dewpoint at $700 \mathrm{hPa}$ which reflects an intrusion of dry air at mid-altitude and the vertical gradient of the temperature between $850 \mathrm{hPa}$ and $500 \mathrm{hPa}$. It does not require a thermodynamic diagram for the calculation. The simulated KI ( 33) indicates a high probabil- ity ranged between $60 \%$ and $80 \%$ for the development of a storm. In the case of the observation, the KI index reaches 28 and the probability ( $40 \%$ to $60 \%$ ) is low.

\section{Conclusions}

The aim of this work was to analyze the ability of the regional atmospheric model (MAR) to both represent and reproduce the atmospheric disturbance over West Africa characterized by the scarcity and/or the space and time discontinuities in the data. The analysis of the behaviour of the model at the meteorological scale constitutes a preliminary step to use this climatic model as a meteorological one. MAR was forced with the ERA-40 reanalyses and a squall line documented during the HAPEXSahel experiment was simulated. Various data, such as sounding and meteosat- 4 images were used. The lack of sounding data during 20, 22 and 23 August 1992 constrained us to study only the squall line during 21 August 1992 at 12.00 UT and at 15:00 UT. The simulated squall line seemed to be shifted eastward when comparing with the satellite image. That was explained by the 30 -minutes lag between the model outputs and the satellite images.

The horizontal wind field at $650 \mathrm{hPa}$ showed that MAR reproduced and integrated the disturbances at the synoptic scale. The simulated zonal wind and a northward reversal signs of potential vorticity (PV) exhibited three vortices. The reinforcement of the PV gradient sign-reversal on the AEJ area is a characteristic of that West African region. The organized convection in that region influences the barotropic and baroclinic instabilities. The model neglected the downdrafts within the cloud except those in front of the squall line. Only the updrafts were well simulated.

The analysis of soundings showed lower simulated characteristic levels than in the observation. The moisture simulated by MAR could be responsible of such difference. The stability indexes were dependent on the moisture of the lower layers and explained the higher simulated indexes than the observations. Such situation helps in intensifying the stormy pattern of the simulated disturbance.

Despite some differences with the observational data, MAR showed an ability to reproduce the major characteristics of the mesoscale convective disturbances. The present simulation brings opportunities in both studying mesoscale systems and converting a climate model into a meteorological one. That could be a valuable tool to study climate change impacts on the West African countries by simulating recent weather phenomena and to forecast new events. However, corrected input data have to be used in the model to improve the simulation and the understanding of the West African climate. Such initiatives, which represent an extrapolation of the model, are encouraged to better explain the observed phenomena 
and to increase our warning capacity for severe weather conditions in that region. That is the focus of the program Young Team Associated to IRD (JEAI) named Littoral, Oceanic and Climate Analysis at the North of the Gulf of Guinea (ALOC-GG) and financed by the French Institute of Research and Development (IRD).

\section{Acknowledgements}

We thank the University of Cocody (Abidjan, Côte d'Ivoire), the geophysical station of LAMTO and the Laboratory of Atmospheric Physics and Fluid Mechanics (LAPAMF) which allowed us to complete this work. We also thank the Université Catholique de Louvain (UCL, Louvain-la-Neuve, Belgium) and the Institute of Astronomy and Geophysics Georges Lemaitre which provided the MAR and scientific expertise. We acknowledge Dr. Hubert Gallée for his frequent help and to Pr. Jean-Pascal van Ypersele for his useful advices.

\section{REFERENCES}

[1] S. E. Nicholson, B. Some and B. Koné, "An Analysis of Recent Rainfall Conditions in West Africa, Including the Rainy Seasons of the 1997 El Niño and the 1998 La Niña Years," Journal of Climate, Vol. 13, No. 14, 2000, pp. 2628-2640. doi:10.1175/1520-0442(2000)013<2628:AAORRC $>2.0 . C$ $\underline{\mathrm{O} ; 2}$

[2] L. Le Barbé, T. Lebel and D. Tapsoba, "Rainfall Variability in West Africa during the Years 1950-1990," Journal of Climate, Vol. 15, 2002, pp. 187-202. doi:10.1175/1520-0442(2002)015<0187:RVIWAD $>2.0$.C $\underline{\mathrm{O} ; 2}$

[3] L. Le Barbe and T. Lebel, "Rainfall Climatology of the HAPEX-Sahel Region during the Years 1950-1990," Journal of Hydrology, Vol. 188-189, 1997, pp. 43-73. doi:10.1016/S0022-1694(96)03154-X

[4] N. D'Amato and T. Lebel, "On the Characteristics of the Rainfall Events in the Sahel with a View to the Analysis of Climatic Variability," International Journal of Climatology, Vol. 18, No. 9, 1998, pp. 955-974. doi:10.1002/(SICI)1097-0088(199807)18:9<955::AID-JO C236>3.0.CO;2-6

[5] V. Mathon and H. Laurent, "Life Cycle of the Sahelian Mesoscale Convective Cloud Systems," Quarterly Journal of the Royal Meteorological Society, Vol. 127, No. 572, 2001, pp. 377-406. doi:10.1002/qj.49712757208

[6] L. M. Druyan, M. Fulakeza and W. Thiaw "Regional Model Simulations of African Wave Disturbances," Journal of Geophysical Research, Vol, 105, No. D6, 2000, pp. 7235-7255. doi:10.1029/2000JD900017

[7] O. Brasseur, "Mesoscale Modeling of Extreme Meteorological Events of Belgium," Ph.D. Thesis, Université Catholique de Louvain, Louvain, 1999.

[8] R. Ramel, H. Gallee and C. Messager, "On the Northward Shift of the West African Monsoon," Climate Dynamics,
Vol. 26, 2006, pp. 429-440. doi:10.1007/s00382-005-0093-5

[9] E. Vanvyve, N. Hall, C. Messager, S. Leroux and J.-P. Van Ypersele, "Internal Variability in a Regional Climate Model over West Africa," Climate Dynamics, Vol. 30, No. 2-3, 2008, pp. 191-202. doi:10.1007/s00382-007-0281-6

[10] R. Ramel, "Etude des Processus de Surface sur le Climat en Afrique de l'Ouest," Ph.D. Thesis, Université Joseph Fourier de Grenoble, Grenoble, 2005.

[11] W. Moufouma-Okia, "Modelisation Climatique de l'Afrique de l'Ouest avec le Modèle Regional MAR," Ph.D. Thesis, Institut National Polytechnique de Grenoble, Grenoble, 2003.

[12] J. P. Goutorbe, T. Lebel, A. Tinga, P. Bessemoulin, J. Brouwer, H. Dolman, T. Engman, J. H. C. Gash, M. Hoepffner, P. Kabat, Y. H. Kerr, B. Monteny, S. Prince, F. Sad, J. Sellers and J. Wallace, "HAPEX-Sahel: A LargeScale Study of Land Atmosphere Interactions in the Semi-Arid Tropics," Annales Geophysicae, Vol. 12, No. 1, 1994, pp. 53-64. doi:10.1007/s00585-994-0053-0

[13] H. Gallee and G. Schayes, "Developpement of a Three Dimensional Meso-Y Primitive Equations Model. Katabatic Wind Simulation the Area of Terra Nova Bay, Antartica," Monthly Weather Review, Vol. 122, 1994, pp. 671-685.

doi:10.1175/1520-0493(1994)122<0671:DOATDM $>2.0$. $\underline{\mathrm{CO} ; 2}$

[14] H. C. Davies, "A Lateral Boundary Formulation for Multi-Level Prediction Models," Quarterly Journal of the Royal Meteorological Society, Vol. 102, No. 432, 1976, pp. 405-418.

[15] D. R. Durran, "Numerical Methods for Wave Equations in Geophysical Fluid Dynamics," Springer-Verlag, Berlin, 1999, p. 465.

[16] J. B. Klemp and D. K. Lilly, "Numerical Simulation of Hydrostatic Mountain Waves," Journal of Atmospheric Sciences, Vol. 35, No. 1, 1978, pp. 78-107. doi:10.1175/1520-0469(1978)035<0078:NSOHMW >2.0. $\mathrm{CO} ; 2$

[17] D. R. Durran and J. B. Klemp, "A Compressible Model for the Simulation of Moist Mountain Waves," Monthly Weather Review, Vol. 111, No. 12, 1983, pp. 2341-2361. doi:10.1175/1520-0493(1983)111<2341:ACMFTS $>2.0 . \mathrm{C}$ $\underline{\mathrm{O} ; 2}$

[18] V. Ntezimana, "Simulation d'un Front Côtier avec un Modèle Atmospherique Regional Comprenant une Représentation Explicite de la Microphysique des Nuages," Ph.D. Thesis, Universit Catholique de Louvain, Louvain, 1993.

[19] E. Kessler, "On the Distribution and Continuity of Water Substance in Atmospheric Circulation," American Meteorological Society, Vol. 10, No. 32, 1969, p. 84.

[20] E. Kessler, "On Accumulation of Water Substance in a Column of Rising Air," Atmosphere-Ocean, Vol. 20, No. 1, 1982, pp. 62-68. doi:10.1080/07055900.1982.9649129

[21] E. Kessler, "On the Continuity and Distribution of Water Substance in Atmospheric Circulation," Atmospheric Research, Vol. 38, No. 1-4, 1995, pp. 109-145. 
doi:10.1016/0169-8095(94)00090-Z

[22] P. Bechtold, E. Bazile, F. Guichard, P. Mascart and E. Richard, "A Mass Flux Convection Scheme for Regional and Global Models," Quarterly Journal of the Royal Meteorological Society, Vol. 127, No. 575, 2001, pp. 869886. doi:10.1002/qi.49712757309

[23] J. S. Kain and J. M. Fritsch, "A One-Dimensional Entraining/Detraining Plume Model and Its Application in Convective Parameterizations," Journal of Atmospheric Sciences, Vol. 47, No. 23, 1990, pp. 2784-2802. doi:10.1175/1520-0469(1990)047<2784:AODEPM>2.0. $\mathrm{CO} ; 2$

[24] ECMWF ERA-40, "Reanalyses Data,” 2011. www.ecmwf.int

[25] University of Wyoming, "Sounding Database," 2011. http://weather.uwyo.edu/upperair/sounding.html.

[26] R. A. Houze, "Structure and Dynamics of a Tropical Squall Line System Observed during GATE," Monthly Weather Review, Vol. 105, 1977, pp. 1540-1567. doi:10.1175/1520-0493(1977)105<1540:SADOAT $>2.0 . C$ $\underline{\mathrm{O} ; 2}$

[27] F. Roux, "The West African Squall Line Observed on 23 June 1981 during COPT 81: Kinematics and Thermodynamics of the Convective Region," Journal of Atmospheric Sciences, Vol. 45, 1988, pp. 406-426. doi:10.1175/1520-0469(1988)045<0406:TWASLO >2.0.C $\underline{\mathrm{O} ; 2}$

[28] M. Desbois, T. Kayiranga, B. Gnamien, S. Guessous and L. Picon, "Characterization of Some Elements of the Sahelian Climate and their interannual Variations for July 1983, 1984 and 1985 from the Analysis of METEOSAT ISCCP Data," Journal of Climate, Vol. 1, 1988, pp. 867904.

doi: $10.1175 / 1520-0442(1988) 001<0867$ :COSEOT $>2.0$.C $\underline{0 ; 2}$

[29] A. G. Laing, J. M. Fritsch and A. J. Negri, "Contribution to Mesoscale Convective Complexes to Rainfall in Sahelian Africa: Estimates from Geostationary Infrared and Passive Microwave Data," Journal of Applied Meteoro$\log y$, Vol. 38, No. 7, 1999, pp. 957-964. doi:10.1175/1520-0450(1999)038<0957:COMCCT $>2.0$. $\mathrm{CO} ; 2$

[30] Y. Lemaitre, "Etude Thermodynamique et Dynamique des Lignes de Grains Tropicales Observées à Korhogo Pendant l'Expérience COPT 79," Ph.D. Thesis, University Paris 7, Paris, 1981, p. 198.

[31] D. P. Rowell and J. R. Milford, "On the Generation of African Squall Lines," Journal of Climate, Vol. 16, 1993 , pp. 1181-1193. doi:10.1175/1520-0442(1993)006<1181:OTGOAS $>2.0 . C$ $\mathrm{O} ; 2$

[32] Y. L. Chen and Y. Ogura, "Modulation of Convective Activity by Large Scale Flows Pattern Observed during GATE," Journal of Atmospheric Sciences, Vol. 39, No. 6, 1982, pp. 1260-1279. doi:10.1175/1520-0469(1982)039<1260:MOCABL $>2.0$. $\mathrm{CO} ; 2$

[33] K. Y. Kouadio, L. A. T. Machado and J. Servain, "Tropical Atlantic Hurricanes, Easterly Waves and West Af- rican Mesoscale Convective Systems," Advances in Meteorology, Vol. 2010, 2010, Article ID: 284503. doi: $10.1155 / 2010 / 284503$

[34] R. J. Reed, D. C. Norquist and E. Recker, "The Structure and Properties of African Wave Disturbances as Observed during Phase III of GATE," Monthly Weather Review, Vol. 116, No. 3, 1977, pp. 824-860. doi:10.1175/1520-0493(1988)116<0824:AEOTPO $>2.0 . \mathrm{C}$ $\underline{\mathrm{O} ; 2}$

[35] G. M. Barnes and K. Sieckman, "The Environment of Fast and Slow Moving Tropical Mesoscale Convective Cloud Lines," Monthly Weather Review, Vol. 112, 1984, pp. 1782-1794.

doi:10.1175/1520-0493(1984)112<1782:TEOFAS $>2.0 . C$ $\underline{\mathrm{O} ; 2}$

[36] J. L. Redelsperger, A. Diongue, A. Diedhiou, J.-P. Ceron, M. Diop, J.-F. Gueremy and J.-P. Lafore, "Multi-Scale Description of a Sahelian Synoptic Weather System Representative of the West African Monsoon," Quarterly Journal of the Royal Meteorological Society, Vol. 128, No. 582, 2002, pp. 1229-1257. doi: $10.1256 / 003590002320373274$

[37] J. Charney and M. E. Stern, "On the Stability of Internal Baroclinic Jets in a Rotating Atmosphere," Journal of Atmospheric Sciences, Vol. 19, No. 2, 1962, pp. 113-126. doi:10.1175/1520-0469(1962)019<0159:OTSOIB $>2.0 . C$ $\mathrm{O} ; 2$

[38] R. W. Burpee, "The Origin and Structure of Easterly Waves in the Lower Troposphere of North Africa," Journal of Atmospheric Sciences, Vol. 29, No. 1, 1972, pp. 77-90.

doi:10.1175/1520-0469(1972)029<0077:TOASOE $>2.0 . \mathrm{C}$ $\underline{\mathrm{O} ; 2}$

[39] R. A. Jr. Houze, "Mesoscale Convective Systems," Review of Geophysics, Vol. 42, No. 4, 2004, Article ID: RG4003.

[40] J.-P. Lafore and M. W. Moncrieff, "A Numerical Investigation of the Organization and Interaction of the Convective and Stratiforme Regions of the Tropical Squall Lines," Journal of Atmospheric Sciences, Vol. 46, No. 4, 1989, pp. 521-544.

[41] C. A. Doswell, "The Distinction between Large-Scale and Mesoscale Contribution to Severe Convection: A Case Study Example," Weather Forecast, Vol. 2, No. 1, 1987, pp. 3-16. doi:10.1175/1520-0434(1987)002<0003:TDBLSA $>2.0 . C$ $\mathrm{O} ; 2$

[42] A. Diongue, J.-P. Lafore, J.-L. Redelsperger and R. Roca, "Numerical Study of a Sahelian Synoptic Weather System: Initiation and Mature Stages of Convection and Its Interactions with the Large-Scale Dynamics," Quarterly Journal of the Royal Meteorological Society, Vol. 128, No. 584, 2002, pp. 1899-1927. doi:10.1256/003590002320603467

[43] J. G. Galway, "The Lifted Index as a Predictor of Latent Instability," Bulletin of the American Meteorological Society, Vol. 37, 1956, pp. 528-529.

[44] J. J. George, "Weather Forecasting for Aeronautics," Academic Press, London, 1960, p. 673. 